\title{
Réquiem por la informalidad
}

\author{
Fernando Bobbio R.* \\ Departamento Académico de Filosofía
}

JOSÉ MARÍA

in memorian

La vida es una incesante búsqueda de (o lucha por conseguir) cierto equilibrio o estabilidad que, a penas alcanzando, empieza a perderse o deteriorarse. En los organismos individuales este estado ideal se llama homeostasis'; y el proceso por el que esta homeostasis se logra, se pierde, se recupera y se vuelve a perder es el ciclo homeostático o ciclo motivacional.

La homeostasis se refiere a la totalidad de los factores que afectan a un organismo dado; pero, para poder graficar el proceso, aislemos una variable, el hombre. Un individuo está, en un momento dado, completamente saciado pero, al cabo de algunas horas, A) empieza a sentir hambre; esta sensación (o necesidad) lo impulsa a B) la búsqueda de comida; la obtención de ésta significa C) la satisfacción dé la necesidad, Fa saciedad u homeostasis. Con el paso del tícmpe, la necesidad reapareeefáy el proceso se repite a lo largo de toda la vida del individuo.

A nivel de las sociedades, se puede establecer una analogía entre la homeastasis y ese estado de satisfacción o, cuando menos, de tranquilidad que existe entre los estados o entre los diversos grupos que conforman un estado y que se denomina status quo.

( $\mathrm{Y}$ entre los individuos - o las familias- que integran la sociedad, se establece el status vitae). El status quo se sanciona o reconoce en el orden legal de cada Estado o en el orden legal internacional.

* Profesor Emérito.

1 W.B. Cannón, The Widson of the Body. N.Y., Norton, 1932.

LETRAS (Lima), 94: 59-68,1997 
Con la homeostasis, el status quo (o el status vitae) está en constante cambio. Debido a la tendencia a la motorrecepción ${ }^{2}$, sólo notamos o notamos sobre todo los cambios bruscos, rápidos, violentos o sanguinarios. Ya hace más de veinticinco siglos la Musa Jonia reconoce que $\pi \tau \tau^{\prime} \lambda \varepsilon \mu \circ \varsigma_{\text {es }}$ rey y padre de todo y, hasta hace poco, el slogan de este siglo agonizante ha sido que la violencia es la comadrona de la historia. Pero también hay cambios graduales, lentos y pacíficos.

¡Oh Lima, oh dulce Lima, ciudad de los amores en ti sí que los tiempos pasados son mejores!

En pleno siglo XX, Lima dormitaba su secular sueño subtropical. Cierto que había sufrido saqueos, matanzas, revoluciones, invasiones y hasta la ocupación de ejércitos extranjeros (argentinos, chilenos, colombianos, chilenos nuevamente) pero, pasadas esas conmociones, las tres veces coronada ciudad de los virreyes volvía a su letargo. El Poeta suspiraba por los tiempos idos, cuando "el virrey constelado de medallas el peeho // penetraba a los sones del broncíneo clarín" en lo que todavía se considera la casa del Pizarro.

Poetisos y poetisas rascaban su guitarra (siguen haciéndolo) invocando la brisa perfumada que pasea del puente a la alameda y añorando las cabalgatas del barrancol (os amancaes. Fntuno.de los mayores alardes de este despliegue de huachaferíaj tuö de los mejores literatos nacionales reduce el Perú a su inmodesta persona.

Pero si "Lima es el Perú" nunca fue cierto, sí lo es que Lima expoliaba al resto del país sin retribución alguna. Los poquísimos servicios de salud o educación se encontraban en casi todos concentrados en la capital, mientras que el resto del país vegetaban en el más absoluto abandono. Recién en la segunda mitad de este siglo un presidente toma conciencia de este hecho y empieza a tratar de remediarlo.

En forma casi simultánea, movidos por ese abandono en que los sucesivos desgobiernos de la república tenían asumida a la inmensa mayoría de los peruanos, Lima empieza a ser invadida por oleadas de provincianos que buscan mejores condiciones de vida y oportunidades de progreso para

2 J. von Uexkull, Idecas para una concepción biológica del mundo. Madrid, Calpe, 1922, p. 158ss. 
sus hijos. Estos invasores se establecieron dónde y cómo pudieron. Pero todo terreno, así esté deshabitado, desaprovechado, descuidado o abandonado tiene propietario (por ello, filius hominis non habet ubi caput reclinet $\mathrm{y}$, a veces, tampoco lugar para sus cenizas); así pues, la primera reacción fue tratar de desalojar a los recién llegados. Pero esto no fue posible. Así nacieron los barrios marginales o barriadas o pueblos jóvenes o asentamientos humanos que rodean la ciudad y cuyo surgimiento ha continuado casi hasta hoy pues, en la década anterior, grandes masas de campesinos fueron desalojados de sus tierras por la violencia terrorista que los obligó a buscar la relativa seguridad de las ciudades, sobre todo la de la capital.

Pero no basta con tener una vivienda, se necesita también una fuente de ingresos. Desçartada la agricultura (su ocupación tradicional), están las fábricas y la construcción para dar empleo a la enorme masa de inmigrantes desocupados; pero la demanda de trabajo es mucho mayor que la oferta.

Entonces, demostrando que su taboriosidad e iniciativa valen tanto (o más) que la de los inmigrantes extranjeros (y mucho más que las de ese malhadado híbrido que es el criollo), los inmigrantes del Perú profundo también invadieron el comercio y la pequeña empresa cuyo ejercicio estaba reservado casi exclusivamente a europeos o asiáticos (y a su acriollada descendencia). Lobhicieron eareciendo detantecedentes, de recursos materiales y de ayuda. Másbien tuvieron que enfrentar o esquivar (y esto más que lo otro), las mil y una artimanas con las que la burocracia hispana (colonial o republicana) pretende ( $\mathrm{y}$ muchas veces lo logra), anular la iniciativa y el espíritu de empresa de sus súbditos.

Para evitar las vallas puestas por esta burocracia ineficiente, haragana y envidiosa, cuyo "favor" se obtiene por la coima,la actividad de estos nuevos comerciantes y pequeños empresarios tuvo que ser informal. Su surgimiento y su consolidación fue un proceso gradual y pacífico de casi cuatro décadas en las cuales las máximas autoridades (varios alcaldes y más de un presidente), les concedieron status quo de reconocimiento casi oficial.

Además, el éxito logrado (que hizo de la informalidad objeto de estudio de varios trabajos muy serios el más famoso de los cuales fue $\mathrm{El}$ otro Sendero), permitió que el comercio y la pequeña empresa informales fuesen el principal mecanismo económico que, aquí en Lima, permitió que 
miles de peruanos pudiesen paliar los efectos de la crisis que en la novena década de este siglo, se agudizó en forma catastrófica. De no ser por las posibilidades que ofrecía la actividad informal, varios miles de jóvenes hubiesen tenido que optar entre morirse de hambre o dedicarse a la delincuencia (y, ¿por qué no a la delincuencia terrorista?).

No es, pues, aventurado afirmar que este sistema incoherente en que vivimos cuyos "paladines" (el alcalde entre ellos), denominan democrático, liberal, humanitario y católico a un tiempo, que arrasó con aplanadoras los puestos de los informales y que, sin ninguna consideración desalojó a hombres, mujeres, niños y ancianos a bombazos, manguerazos y garrotazos y que, de haber habido una reacción a ultranza, no hubiese dudado en balearlos (y llamarlos terroristas), debe su supervivencia, en alguna medida, a que sus víctimas de hoy, ayer no quisieron (no pudieron o no se atrevieron) a ser sus víctimarios.

La violencia que las "fuerzas del orden" (la polícia y los "cascos azules"), azuzadas por el alcalde y sus acólitos, emplearon contra estos pacíficos comerciantes y sus farnilias, fue algo inédito en nuestro medio y superó con mucho, tanto en amplitud como en intensidad, la que nos muestra la televisión cada cierto tiempo para recordarnos las atrocidades de los terribles nazis contra Ios pobres comerciantes jưdíos $\mathrm{Y}$ todo esto ocurrió con el atronador aplauss de una claque mercenarias y ante la indiferencia del resto de la población.

El único coherente de los actores fue el alcalde que puso en práctica el programa "doctrinario" pepecista que sólo admite la gran empresa. Las anteriores "autoridades" que habían aceptado y casi oficializado la informalidad callaron a rabiar. El ex-presidente que se afana en parlotear cuantas veces puede, enmudeció. Y, en el colmo de los colmos, el ex-alcalde stalinista (o ex-stalinista) que, debía haber marchado con los empleados municipales despedidos y con los informales en trance de ser desalojados, sólo se "sacrificó" mirando tras el ex-pepecista en defensa de su propia estabilidad laboral (y...¿de un pequeño incremento para sus depósitos bancarios?).

Los antiguos colegas de estos dos personajes (que serían pintorescos de no haber sido nefastos para los peruanos), que todavía sobreviven, también eludieron el problema con toda decisión y valentía. 
En todo caso, si pecaron por omisión en este asunto, muy poco después se reinvindicarían cuando, recordando que son charlamentarios elegidos por el pueblo para defender sus derechos, se enfrascarían en un ardoroso debate en torno a cuál de las partes (Summers o Tribschers o algo así), eran los accionistas mayoritarios en un negocio de muchos millones de dólares. Por supuesto que esto sí es del más profundo y auténtico interés nacional. En cambio que un Huamán o una Poma pierdan su lugar en una acera (que debe estar "limpia") y queden sin poder ganar algo con que alimenta a sus hijos eso, carece de importancia.

El amparo, la defensora, la madre de los pobres, de los débiles,de los oprimidos de los desvalidos recordó a tiempo la prescripción de su maestro (regnum meum non est de hoc mundo), que una de sus reglas es el silencio y que, por último, los pobres (y mientras más míseros mejor), ya tienen asegurado el reino de los cielos (regnum dei) y, así, ¿para qué quieren más? En cambio, los pobrecitos capitalistas sí requieren el pronunciamiento de los pontífices; así pues, también la iglesia interyino en el litigio de los millones.

Finalmente, la llamada "libertad de prensa" sirvió para que los mercenarios que la perpetran gastasen sus plantas aplauciendo a rabiar el abuso, la prepotencia y la violencia con que fueron despojados y desalojados los comerciantes informales $\mathrm{y}$ susfamilias. Letras

\section{"Jorge Puccinelli Converso"}

\section{REQUIESCAT IN PACE}

La cuestión está concluida y esa informalidad muerta. (Pero el cadáver ¡ay!, ya está muerto) Pero, ¿fue necesario perpetrar ese asesinato?, ¿cuáles fueron sus motivos?

Hay varias razones por las que no se debió haber terminado con el comercio informal en Lima (medida que han copiado servilmente los demás alcaldes). La primera que salta a la vista, es la de la forma en que se perpetró el crimen. No hay ninguna justificación racional para excusar la violencia casi bélica con que rompió un status quo que había sido alcanzado en forma paulatina y pacífica a lo largo de varias décadas y que había sido respetado por todos los alcaldes anteriores. 
Esa tremenda dosis de violencia que hemos presenciado ha contribuido (seamos o no conscientes del hecho), a envenenar aún más nuestras mentes y, en un grado mucho mayor y difícilmente detectable por ahora, la de los menores. No se ha tratado de los soldados de dos países en guerra y, ni siquiera, de policías contra delincuentes. Ha sido la mera violencia de la fuerza contra la necesidad.

En segundo lugar y esto es más importante, pese a los éxitos de los últimos años, la crisis no ha sido superada. Somos uno de los países latinoamericanos (limitemos la comparación para no deprimirnos), con un mayor índice de pobreza extrema. La desocupación y el subempleo campean en nuestras ciudades. El comercio informal paliaba en algo esta situación. Es cierto que algunos de los comerciantes informales se han formalizado, pero no es el caso de la mayoría que ha pasado a incrementar las filas de desocupados o de subempleados. (Y no es muy difícil que la desocupación conduzca al delito).

Desde que empezaron las invasiones de provincianos, los buenos limenses estuvieron proyectando cómo deshacerse de estos nuevos e incómodos vecinos. En un relato bastante bien logrado (y leno de enseñanza) ${ }^{3}$, vemos a una old lady del ancient régime (la mamama del narrador) que, yendo por el "jirón", manita con manita con su nietecito, le va contando cómo era Lima varias décadas atrás, "cuando no estaba llena de tantocholo ăpestoso"a. de Letras

\section{"Jorge Puccinelli Converso"}

Tratando de remediar tan catastrófica situación, ya en los lejanos cincuentitantos, un legislador propuso dar una ley prohibiendo a los peruanos a moverse de su lugar de origen. Como es obvio, no puede formalizarse una propuesta de este tipo; pero pueden tomarse medidas que, directamente, lleven a este objetivo. La principal acaba de ser dada sin que muchos se percaten de ello. Por lo pronto, la vieja dama ya podría estar happy (como lo está toda la huachafería limeña que, motorizada, pasa y repasa por las estrechas calles del centro polucionando el ambiente cada vez más).

Así pues, el alcalde ha "limpiado" la ciudad; pero no de basura, sino de gente. Ya no están los comerciantes informales (casi todos de origen andino) que "ensuciaban" calles y plazas, parques y avenidas. Los servios, menos hipócritas que los limeños, dirían que se halogrado la "limpieza étnica" de la ciudad.

3 Jaime Bayly, Los últimos días de La Prensa. Lima, 1995. 
Esta "limpieza" se relaciona directamente con el slogan oficial del alcalde: "Lima renace, su gente lo hace". Se nos informa que la ciudad ha estado muerta; ¿cuándo?, cuando las calles del centro estaban atestadas de gente (vendedores, compradores, transeúntes). Con su varita mágica el alcalde hace renacer Lima: aceras casi vacías y pistas repletas de tubos de escape arrojando sus gases letales a toda velocidad.

El slogan sería insultante si hubiese sido pensado; pero nuestras expresiones no sólo salen del cerebro; pueden salir del corazón, del hígado y, aún, de los bolsillos. Y allí radica el fondo de la cuestión que empezó como intento no deliberado de andinizar la ciudad en su punto neurálgico, el comercio. Con su agudeza habitual Pablo Macera se percata de este fenómeno y lo mira con optimismo ${ }^{4}$, pero no imaginó la violencia criminal con que terminaría este experimento no planeado que fue el choque (no buscado por quienes sólo pretendían sobrevivir en una ciudad que les era tan angosta como ajena), entre dos Weltanschauungen incompatibles.

Una basada en el tratado humano entre dos personas que truecan o regatean; la otra, que sólo acepta una relación deshumanizada entre el comprador y la caja registradora (la cajera es una simple iniermediaria). Este proceso culmina con la "relación" plenamente onanística (que ya funciona parcialmente) del cliente coños corentos de máquinasque serán sus únicos "interlocutores" en un inmensogalpón "limpio" de cualquier otro ser humano.

Finalmente remarquemos que no sólo es la eliminación de un modus vivendi; se corta de raíz ( $\mathrm{y}$ de eso se trata), la posibilidad de que los provincianos entren a Lima. Es la negación de lo que antropólogos, etnólogos o sociólogos piden para los inmigrantes que llegan a la ciudad (en países como el nuestro), estaciones de aclimatación en que se vayan adaptando al nuevo medio).

En lo sucesivo, los provincianos que lleguen a Lima, si bien pueden contar con las viviendas de sus familiares, carecerán, casi en absoluto, de la posibilidad de mantenerse. La canción de la Sonora Matancera es demasiado optimista (Cuatro puertas hay abiertas, para el que no tiene dinero, /el hospital y la cárcel, la iglesia y el cementerio).

4 Entrevista reproducida en el Directorio de la Universidad Nacional Mayor de San Marcos. 
Las iglesias nunca han estado abiertas al pobre (excepto en el más superficial de los sentidos); y hospitales y cementerios cobran por ingreso y por estacionamiento.

Al inmigrante provinciano en Lima ya sólo le queda, además de "mendigar o morir", la posibilidad de delinquir y terminar en la cárcel, la única institución cuyas puertas ha mantenido siempre abiertas para $\mathrm{cl}$ pobre la civilización cristiana.

Por ello conviene recordar el cristianísimo interés demostrado por el alcalde hacia los más necesitados. Casi simultáneamente al desalojo de los informales, se ejecutó también la remodelación de la plaza de armas. Con lo que allí se gastó innecesariamente (fue el único rincón cuya limpieza y ornato se respetaron siempre), bien pudieron haberse habilitado puestos (gratuitos o a precios muy bajos), para todos aquellos (un buen número) que, por falta de recursos, no pudieron adquirir alguno de los que se les ofrecieron.

Llegamos a una de las "justificaciones" del desalojo, el argumento de la limpieza y el ornato de la ciudad. Pero no es muy difícil responder que para imponer y mantener la limpieza, lo que se requiere es un buen servicio de limpieza de los lugares públicos, nada más.

En cuanto al ornato, dosensatoe en uppístan pobre, es posponer las ansias ornamentales. No es coherente tener una ciudad cuyo ornato y lujo iguale o superen a los de cualquier otra ciudad, con jardines versallescos, plantas exóticas y juegos de agua multicolores, cuando la gran mayoría de los habitantes del país viven en la pobreza y un buen porcentaje en la pobreza extrema o miseria, es decir, crónicamente enfermos y al borde de la inanición. Que Lima ya tenga enclaves en los que sus habitúes puedan sentirse en Miami (su patria "espiritual"), no significa que toda ciudad tenga que convertirse en una réplica de disneyland.

El argumento "limpieza/ornato" está íntimamente ligado al supuesto interés por atraer a los turistas. "¿Qué dirán los turistas de una ciudad tan descuidada?”, podría preguntar la cándida abuelita (¿no se habría llamado Eréndira?), del narrador ya mencionado. La cuestión es menos ingenua y más profunda; la ciudad, ¿es de los turistas o de los peruanos? La respuesta ha sido dada, se ha desalojado a los peruanos de las calles de la ciudad para que los 
turistas puedan pasear sin ninguna incomodidad y apreciar las bellezas citadinas. Pero también hay otro aspecto que se suele ocultar, el atractivo de Lima para el turista es un mito. El turista pasa por aquí porque está obligado; si pudiese ir directamente al Kosko o a Huaraz (para citar sólo dos destinos más apetecibles que Lima), lo haría, sin ninguna duda y demostrando un mínimo de buen gusto. Casi todas las "grandes" ciudades de hispanoamérica son copias de segunda categoría (o tercera) del urbanismo español que, a su vez y salvo en las zonas de fuerte influencia árabe, es uno de los menos interesantes de Europa.

La otra cuestión, si Lima es de los autos o de los peatones (que somos la inmensa mayoría de los peruanos), también ha quedado zanjada del modo más inconveniente y desventajoso; aunque el propio afán de salvar o conservar la ciudad aconseja prohibir la polución provocada por los motores de los carros que se han lanzado al centro en masa y a toda velocidad.

El único argumento que podría parecer serio es que el comercio informal elude los impuestos y fomente el contrabando; pero tampoco es consistente pues, por primera yez, hay un organismo que está controlando correctamente (y quizá incluso con demasiado rigor), que los ciudadanos cumplan con sus obligaciones tributarias. La Sunat no hubiese tenido ninguna dificultad en integrar esos informales a su lista de tributarios.

\section{Biblioteca de Letras}

En cuanto al contrabando su centrol es incumbencia de las aduanas; que siempre haya existido no es, en absoluto, responsabilidad de los comerciantes informales que, simplemente, aprovecharon una situación (un status quo ilegal) preexistente que continúa y continuará. Además, dentro de la más plena legalidad, hay todo un ejército de empleados de las compañías de aviación que entran y salen del país a toda hora y a los que les está permitido ingresar cierta pequeña carga que no les está prohibido (sería imposible hacerlo) comerciar.

Casi todos los peruanos que hacen turismo también aprovechan para negociar muchas de las cosas que traen legalmente y que, supuestamente, son para su uso personal. Por si fuese poco, no es muy difícil sobrepasar en algo los límites legales e incrementar el negocio. Así, hay hay muchos turistas que costean sus tours con lo que traen y venden. Esta es una informalidad (no legalidad) que nadie menciona y cuya erradicación nadie pide. 
Para terminar, la última medida del alcalde, el desalojo de los vendedores de comida de la avenida Grau nos recuerda a María Antonieta; se dice que oyendo a los pobres pedir pan y creyendo que se trataba de un capricho extravagante de esas gentes, les explico que si no tenían pan a la mano, abriesen sus alacenas, sacasen las tortas allí guardadas y las comiesen. En nuestro caso, nuevamente se trata del ornato y la limpieza condimentado, además, con el pretexto de la salud. No se ha mencionado, pero podría agregarse el del buen gusto; cómo pueden estas gentes comer en la calle, en medio de la suciedad, del polvo que trae el viento y del humo de los carros; tan fácil que es avanzar unas cuantas cuadras y tan bien que se puede comer en el Sheraton.

En el Estado moderno, los dueños del poder se toman "libertades" que los reyes jamás se permitieron. Y Ysi un pretendiente tuvo que rebajarse a oír misa en contra de sus convicciones para sentarse en un trono, aquí tenemos un pretendiente que se da el lujo de desoír a los pobres. Y los dueños de los negocios "informativos" aplauden a rabiar.
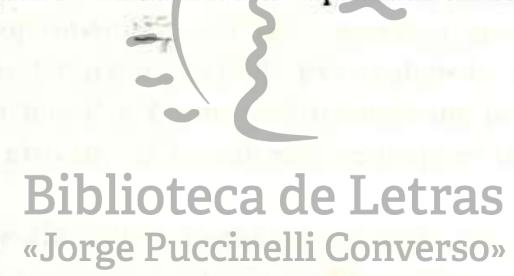